\title{
Process of Supervision of Civil Service Operation by the Commissioner for Civil Service Supervision, in Function of an Efficient Service
}

\author{
Phd. Julejda Gërxhi \\ Department of Law, Faculty of Political and Jurisprudential Science, "Aleksandër Moisiu" University, Durrës, Albania \\ Email:julejda@gmail.com
}

\section{Doi:10.5901/ajis.2015.v4n1p275}

\begin{abstract}
This article aims to reinforce the idea that the process of supervision of the operation of civil service, by the Commissioner for the Sivil Service Supervision, creates the possibility of an efficient public administration in the function of citizens. The realization of this paper is based on the analytical method and are analyzed the advantages that the establishment and functioning of the institute of the Commissioner for the Civil Service Supervision bring, referring to the analysis of powers and responsibilities that it is empowered by the law "On civil servants". This paper aims to treat the role of the Commissioner for the Civil Service Supervision, in the process of supervision of the civil service, within the competencies that the civil servant law has recognized, analyzing the effectiveness and interventions that it carries out, and the evidence of their advantages. In this way the process of supervision, assists in the correct functionality of the civil service, not only in the inner way of its organization (since the initial stage of recruitment of civil servants in the civil service, up to the assessment of this service, in view of citizens), but mostly at its own responsibility to the citizens.
\end{abstract}

Keywords: Civil Service, supervisory process, decision, recruitment, efficiency.

\section{Introduction}

The civil service law aims to create a stable and efficient public administration.

The current law is conceived as a framework law that governs civil service administration, the legal relationship of civil servants working; their rights and duties; the manner of recruitment; the promotion; performance assessment and disciplinary procedures. This legal act guarantees the right to be employed in the civil service, offering protection through defined rights for civil servants, and also provides for the duties of civil servants.

Practical implementation of these guarantees is achieved through the implementation of a system of efficient and effective management of human resources for the public administration, as well as through the monitoring of this system. The scheme of institutions working to achieve this goal consists of DAP (Department of Public Administration) for public administration institutions; personnel departments in independent institutions and in local administration institutions that carry out the management of the civil service, as well as by the Commissioner for Civil Service Supervision, who has the task of monitoring the system.

The Commissioner for Civil Service Supervision plays this role in the implementation of the law no.152 / 2013 "On the Civil Servant", which defines the supervision of the civil service administration, as one of the powers of this institution.

Specifically, the supervision of civil service is realized by:

1- Supervision conducted through scheduled visits (inspections).

2- Pursuing the enforcement of warning decisions taken by the Commissioner for Civil Service Supervision, as well as measures taken to remedy the legality.

3- Fine penalization to remedy the situation in the case of non-enforcement of warning deciosions taken by the Commissioner for Civil Service Supervision.

\section{Supervision Conducted through Scheduled Visits (Inspections)}

Supervision Civil service supervision through visits in institutions is realized based on an annual plan approved by the Commissioner for Civil Service Supervision. This plan is drawn up taking into account the following criteria:

$>$ Institutions are selected according to the problems arising during the process of reviewing complaints;

$>$ Entities are selected which are not controlled previously. 
This process involves independent institutions, institutions of state administration and local government units.

The conducted supervisions have a wide object including all institutes under the law on civil servants.

Namely:

- Civil service recruitment.

- Promotion and horizontal movement, aspect of career development of civil servant.

- Training of civil servants, a necessary condition for performance improvement and capacity development of the civil service system.

- The process of individual performance assessment of civil servant.

- Implementation of disciplinary procedures by controlled institutions.

- Civil service recruitment

Recruitment in this system, under current law is provided for in Article 20 of Law no.152 / 2013 "On the Civil Servant" and it is a procedure that is performed for any free position in the civil service.

It is an important process which should be done through a selective competition, transparent and fair, respecting the principle of equal opportunity, meritocracy, professional skills, and non-discrimination.

The Commissioner for Civil Service Supervision should show special attention for this institution, in choosing carefully the recommendations that should give, to remedy the situation in cases of violation of the procedures provided for in the law, so that they are efficiently, analysing case by case the situation of the controlled institution , as well as by taking into account the specific circumstances where these institutions perform their activities without risking their normal operation.

If we refer to Law No. 8549, dated 11.11.1999 "Civil Servant Status", this power was exercised by the Civil Service Commission, which came with specific recommendations by supervision of this process.

Recommendations made in cases of violations found were considering:

a) the fact of the inability to terminate at the same time all employment contracts, as this action bring about the suspension of the exercise of the institutution normal functions, for a period, which in the best case lasted 3 months, which was the minimum time the development of a competition procedure required;

b) high financial cost that the process had, which could not be affordable by the controlled entity, to perform simultaneously all competitions;

c) relatively long time needed to fix the consequence judicially.

In this case, the Civil Service Commission took into account the fact that the pursuit of judicial route would be impossible first with the budget of the Civil Service Commission, because legal expenses were added that were related to the fees for registration of application - lawsuits and secondly, the fact that the pursuit of judicial proceedings in districts, required human and logistic resources, which were not sufficient in the Civil Service Commission.

In these conditions the Civil Service Commission ordered the institutions that within the legal announcement deadline (2 months) to compile a detailed work plan for the development of competitions, where to determine via a graph, the sequence and time of development of applications.

Currently, the law no.152 / 2013 "On the Civil Servant", has resolved this institutional impasse, as already recruitments will be done non individually, but on the basis of recruitment into groups according to civil service positions (Article 19, paragraph 1), and appointments in the civil service, specifically the winning candidates, ranging from the one having the highest scores, have the right to choose to be appointed in any position of the group, for which the competition is conducted, as well as in any free position of the same group, which is created free during the validity of the list. (Article 22 paragraph 3 of Law).

In these circumstances The Commissioner for the Civil Service Supervision takes measures that the implementation of this process be monitored by his staff, which conducts supervision in the relevant institutions and oversees the graph implementation, helping the process development in the future.

The pursuit of this procedure, in fact provides significant and prompt results, concerning the recruitment in the civil service, which is the result of the subjects awareness for the implementation of the new law, but also because of a close cooperation and support that the Commissioner for Civil Service Supervision gives to the units of human resources management in these institutions.

- Promotion and horizontal movement, aspect of career development of civil servant

The process of promotion and horizontal movement, stipulated in Article 15 of Law No. 8549, dated 11.11.1999 "Civil Servant Status".

During supervisions conducted over the years, the Civil Service Commission found a low percentage of cases when these procedures are applied. In recommendations this institution gave, it took into account certain circumstances 
which made it objectively difficult the application of this procedure.

This institute became objectively inapplicable in units of local government, it was about municipalities of the third level, in which all job positions were completed through contracts, as the application of parallel movement and promotion, was enabled only if the employee had acquired the status of civil servant.

This ascertained state was clear evidence of emergency of changes in the civil service law, in relation to this institute, to enable the practical application of the principle of career development of civil servants.

Law no.152 / 2013 "On the Civil Servant", in Article 25 and 26 has provided career development procedure of civil servants of the executive category. Specifically, horizontal movement is accomplished through the application of candidates who have gained the status of civil servant, and belong to the same category, but meeting the conditions for parallel movement as well as special requirements for the vacancy. Assessment of applicants is carried out by an internal committee of the respective institution, which realizes the decision making for selecting the most suitable candidate to be appointed to the vacancy, or termination of the procedure without selecting any of the candidates, because they not meet the the general conditions or the special parallel movement. Promotion is realized through the procedure of competition, which is organized by the responsible unit, for one or several positions simultaneously.

This procedure is followed when the completion of vacancy was not achieved through parallel movement, due to failure to meet the criteria by the applicant candidates of the lower or middle managerial category.

If the procedure of promotion does not bring the completion of the vacancy, once again should be reorganized the horizontal movement or the promotion procedure..

By the time of filling the vacancy, is operated with temporary transfers according to the needs the relevant institution pursuant to Article 48 of Law no.152 / 2013 "On the Civil Servant".

The Commissioner for the Civil Service Supervision exercises the right of supervision over these procedures, to identify the violation cases either procedural or of the deadlines set by law, and take measures pursuant to Article 15 of the Law "On the Civil Servant".

- Training of civil servants, a necessary condition for performance improvement and capacity development of the civil service system

One of the rights which is also liability of institutions involved in the civil service, is the participation in training activities organized by the institution during the performance of duty.

Law No. 8549, dated 11.11.1999 "Civil Servant Status", had provided for the supervision of the training process conducted by ITAP \{institute of public administration training IPAD\}, as a duty of the Civil Service Commission, which as an issue regarding this institute, provided that incentives to increase participation in training activities of civil servants, were very few, whereas the training actually should have a direct connection with the career development process. The employee who was highly trained ought to be preferential, especially in cases of parallel movement and promotion, according to this law.

Therefore, to adjust problems for the training institute, were not sufficient the legal instruments that the Civil Service Commission had, but were necessarily required legislative changes, which aimed at determining the incentives to motivate employees to participate in training, which led to adjustment of this process, particularly and detailed legally.

This institute becomes of special importance in conditions when new laws are adopted with a high frequency of preparation of the public administration employees capacity, to implement EU laws.

The qualitative difference in the training field was conducted with the anticipation of the creation of the Public Administration School, which will provide specialized short and long term trainings.

In these circumstances, according to the law no.152 / 2013 "On the Civil Servant", the Commissioner for Civil Service Supervision during supervision, should use as a methodology, the identification of all current trainings conducted by employees, indicating in particular the training institution, the training level, as well as degrees or titles won, for every civil servant of the supervised entity.

But in order that the process of training receive the proper assessment, the Commissioner for the the Civil Service Supervision is assigned to determine the institution's liability to implement all phases this process includes, starting with:

a) collecting the training needs of employees;

b) drafting an annual training plan, as well as

c) sending the training plan to ASPA \{Albanian School of Public Administration), in order to be included in the overall training plan drafted by the institution.

In order to ensure the progress of this process in the proper direction, the implementation of recommendations is monitored by inspectors of the Commissioner for Civil Service Supervision.

In this way the heads of institutions do not have to consider this need of second hand, but were as a necessity to 
make their employees more creative and contemporary.

\section{- The process of individual performance assessment of civil servant}

Performance assessment is a process that has significant implications for a civil servants in several aspects, among which we can mention:

- His confirmation after the trial period;

- termination of the employment relationship after two consecutive negative assessments;

- annual bonus depending on the assessment;

- favoring the parallel movement and promotion;

- resettlement of employees in cases of job positions restructuring.

For this reason the process of assessing individual achievements at work, should be realistic and based on concrete results by the level of objective achievement.

The care for all institutions is mainly directed towards the implementation of formal assessment procedures, such as filling the evaluation forms in all their sections, within the legal limits.

Whereas, given the content of the process, should be realized the differentiation of employees according to levels of assessment 1. "very good"; 2. "good"; 3. "satisfactory"; 4. "not satisfactory".

In the development of the assessment process analyses, should be kept periodically records from the entity responsibles for the performance of the employee during the assessment year, which effectively should accompany the evaluation form, which should be be stored in the personnel file.

This is a legal obligation of the responsible of the entity for employees to be assessed, provided in the Instruction No. 2, dated 07.07.2000 "On the system of individual annual achievements of civil servants", as amended, which again is expected to be amended in accordance with the law no.152 / 2013 "On the Civil Servant".

The task of the Commissioner of Civil Service Supervision is to ascertain subjective attitudes during the assessment of individual performance, which may even result in unrealistic assessments, influenced by various factors, which do not show indeed, objectively, the level in which the civil service is situated.

The pursuit of such a procedure provides the opportunity for employees to not lose their motivation to perform a job with a high level.

The Commissioner for the Civil Service Supervision interferes with recommendations, and in the event of their failure within the legal deadline set by the Commissioner, he undertakes fine penalties, when he determines that:

First: the assessment of individual performance is carried out at a time when the institution's performance measurement is lacking, and consequently it can not be conducted a realistic assessment related to the achievements of the institution.

This concept, "measuring the performance of the institution" has started to articulate as a challenge in the CrossCutting Strategy for Public Administration Reform, 2013-2020.

In this document to which the civil service system occupies an important place, it is provided as a priority the measurement of the institutions performance and the establishment of a closer connection with the measurement of individual performance of employees.

Secondly, Performance evaluation is not reported from the formally perspective and is not accompanied by the payment of bonuses for civil servants, which relate progressively to the level of assessment.

In terms of improvement of the process and the elimination of subjective assessments, the Commissioner for Civil Service Supervision leaves concrete tasks for the personnel unit, especially in terms of training planning in this field for employees charged with the implementation of the assessment scheme, as well as through the superiors control, to supervise the assessment process, extended throughout the calendar year. The assessment report is determined by a specific bylaw, specifically in point 8 "iii" of Instruction No. 2, dated 07.07.2000 "On the system of individual annual achievements of civil servants", as amended by Instruction No. 5, dated .19.12.2007, it is determined that the "authorized officer" must ensure that employees, who are assessed with the overall level 1, "very good" or 2, "good" should not exceed $1 / 3$ of the total personnel number in the group, for each level. This role is performed by the Secretary General or the Director General, in the absence of the Secretary General, in independent institutions and the Director General of the institution in local government units.

- Implementation of disciplinary procedures by controlled institutions

In terms of implementation of procedures for the giving disciplinary measures, subjects entrusted by law to follow them, should be very discreet in their reporting in the administered documentation in personnel files, what materializes this procedure. Specifically, employees who are subject to these measures should be notified to the initiation of disciplinary proceedings should be heard, should present relevant observations and then the institution should provide an 
argued decision. According to Law No. 8549, dated 11.11.1999 "Civil Servant Status", the control of this process is realized by the Civil Service Commission. Regarding the efficiently application of this institute it was estimated that it existed the practical impossibility of implementing several measures that were set out in the above mentioned Law, such as: "the transition to a position of a lower level", as not every institution had the opportunity to apply, in conditions that was always required a free positionto be applied. Furthermore, it was estimated that the variety of disciplinary measures was limited and for this reason, it was found a kind of attraction to give a disciplinary measure, which would have been either of extreme nature: "removal from the civil service", or of a light nature, which in many cases had no real impact to realize its goal. In these conditions, in order that this institute is used efficiently, the law nr.152 / 2013 "On the Civil Servant", provides in detail the types of responsibilities for disciplinary measures (Article 57), as well as the powers and procedures for provision of disciplinary measures (Article 59), based on the principle of proportionality of the measure given to the violation committed, clearly defining the factors affecting the issuance of disciplinary punishment, such as the type of violation, circumstances, conviction, etc. In addition, if we refer to Article 58 of this Law, the variety of disciplinary measures and sanctions, is more simplified and practical for implementation, because now in four disciplinary measures, two of them refer to withholding of salary, or the loss of a higher salary for a certain period of time, which bring the ease of implementation of these measures by the institution itself where is the penalized officer is employed. The process of supervision by the Commissioner for Civil Service Supervision regarding this institute has already been easier, because the applicability of the measures remains under the direct responsibility of the institution where the penalized officer is employed without being justified for their inability to enforce.

\section{Pursuing the Enforcement of Warning Decisions taken by the Commissioner for Civil Service Supervision, as Well as Measures taken to Remedy the Legality}

For an effective supervision of the civil service, the Commissioner for Civil Service Supervision has the power to pursue the enforcement of the warning decisions given under supervision.

This process is based on the verification on site of the situation, immediately after the completion of a legal deadline, which is left to the institutions to remedy the situation. (The legal deadline will be determined in the normative acts of the law)

Pursuing the implementation of the decision must be conducted on an ongoing basis by the working groups which carry out the supervision, materializing it in the act of observation.

In conclusion the Commissioner for the Civil Service Supervision should be expressed by a special decision for each case, and determines the ways to be pursued to carry out the tasks assigned to the act of warning.

Pursuing the implementation of the decision consists of of two key moments:

- The implementation of the recommendations of the Commissioner for the Civil Service Supervision, regarding the institution of acceptance in the civil service.

- The structuring of the institution, upon expiration of the warning deadline.

The structuring of the institution in accordance with the standards required, among which a clear definition of functions and hierarchy for each position, gets a special importance, since in this way employees can be provided with opportunities for clear responsibilities, more achievable, more measurable, to influence the increase of quality of service to citizens.

For this reason, special importance is given to the pursuing of the structuring process of the institution by the Commissioner for the Civil Service Supervision, which is realized by monitoring, and simultaneously by providing ongoing technical assistance, on one hand during supervision, and on the other hand through cooperation with contact persons authorized by these institutions, to communicate with the staff of the Commissioner for the Civil Service Supervision.

This cooperation will positively affect towards the realization of structuring scheme according to the best standards in the civil service, which are already applied in the central administration.

This scheme must be necessarily applied taking into account the specific circumstances in which the local administration operates. Of course we cannot have expectations that the process of structuring in these institutions will move with the same speed as the central administration institutions, for the following reasons:

a. The process of central administration structures has passed through several stages, beginning with a proper study which was conducted by the Department of Public Administration in cooperation with experts from the EU in 2008-2009, which was materialized in the manual for structuring and restructuring of central administration institutions.

Later on it was approved the Decision no.474, dated 16.06.2011 of the Council of Ministers "On defining the 
standards of the procedure to be followed during the drafting and approval of the administrative structures of the institutions of public administration", which sets standards related to construction of structures and organizational structure charts (organigramme) in these institutions.

The process was completed by Law No. 90, dated 27.09.2012 "On the organization and functioning of public administration", which sets standards for the establishment and operation, as well as the executive institutions typologies.

Thus, the process has got the due time passing all necessary stages and training, which has made the institutions responsible for the implementation of new structures according to contemporary standards. This has not happened with the local administration institutions, which causes difficulties and slowness in the process progress.

b. Standardization of structures consistent with the law no.152 / 2013 "On the Civil Servant", touches on a number of managerial level positions, which are abolished or reduced in categories and this reality becomes a great "resistance" of employees, that are currently situated in these institutions, having regard to the influence as well as to the level of salaries.

c. In local government institutions with low number of residents in their territory (municipalities of third categories and fourth) due to low salaries, increase of managerial level positions is found as a tool to attract job candidates with a certain quality threshold of a positive direction and the change of this reality would make them unable to maintain this standard.

d. Another factor which affects and increases the level of difficulty for implementation at local level of standards applied to the central government, is the major difference in salary of civil servants job positions of local administration, with those of the central administration, which belong to the same level or category of the public sector.

e. During the operation of these institutions a series of specific laws are combined which delegate tasks from the central to local government, in the framework of decentralization of power. In general, their implementation necessarily requires from the local government units the establishment of special units that shall pursue their implementation.

For all these reasons mentioned above, standardization of structures in local administration institutions is a difficult challenge that requires a job that shall coordinate the activities of a number of institutions.

The Commissioner for Civil Service Supervision should seriously and steadily commit in this regard.

\section{Fine Penalization to Remedy the Situation in the Case of Non-Enforcement of Warning Deciosions taken by the Commissioner for Civil Service Supervision}

After completion of the supervision procedure, which consists of:

1. The verification of the situation in the institution to ascertain the level of implementation of recommendations after the legal warning deadline;

2. The approval of Act of Verification by the Commissioner for the Civil Service Supervision, where it is materialized the application level or non warning.

If it is determined the failure of the decision of the Commissioner, the process continues beyond with the fine penalization, to the responsible officers, who did not implement the provisions of the decision of the Commissioner for the Civil Service Supervision (Article 15 paragraph 2 of Law no.152 / 2013 "On the Civil servants").

The fine is $20 \%$ to $30 \%$ of the monthly salary of the employees responsible.

In case of further failure of the decision, the Commissioner may impose another penalty of up to $50 \%$ of the monthly salary of the person responsible.

This new experience for the Commissioner for the Civil Service Supervision, will prove successful, due to the determination of individual coercive fines to the responsible officers, who are penalized individually with their salary without leaving the responsibility on the budget of the institution, as stipulated in the previous law.

Decisions on the fine issuing can be appealed before the competent courts for review of administrative disputes.

\section{Conclusions and Recommendations}

* The Commissioner for the Civil Service Supervision during the supervision of civil service, could encounter certain difficulties. Specifically regarding the recruitment process especially in local government bodies are currently found:

a) lack of specialized human resources and financial means needed for correct implementation of the 
recruitment process;

b) lack of suitable candidates, especially in the case of positions that require specific education.

c) relatively low salaries applicable to civil servants in local government institutions, which differ from those of the central institutions.

* However, to increase the efficiency of the recruitment system, and a good management of this system from the Commissioner for the Civil Service Supervision, it is considered very important the new legal procedure of admission to the civil service, anticipating a competition system based entirely on meritocracy, as well as aiming to reduce the time needed to fill vacancies and reduce financial costs. This is possible through the group recruitment, which will be organized based on the anticipated and planned needs of the positions to be filled, as well as through the creation of special structures that will manage the process of competition.

* Similarly, of grat importance is the adoption of bylaws, which should clearly define the procedures to be followed during the implementation process, in accordance with the categories of civil servants, according to the legal provisions.

* The Commissioner for Civil Service Supervision has at his disposal legal tools (individual fine measures) which create the conditions to give quick results and therefore he propels institutional collaborations, which have the ability and legal obligation, to influence, in different ways, according to competencies they have, to contribute to the implementation of the law no.152 / 2013 "On the Civil Servant". To be assessed is the support in this regard that the Supreme State Control, can give to the Commissioner for the Civil Service Supervision.

At the end of the process of supervision, the Commissioner for the Civil Service Supervision may submit to this institution, the Final Report of Supervision, in order to get familiar with the encountered problems.

The Supreme State Control has the possibility of inclusion in the control programs, the encountered problems in supervision materials, which are related to his field of action, especially the problems of structure, employment contracts and the decisions enforcement of the Commissioner for the Civil Service Supervision, and consequently, they may also be reflected in the recommendations that this institution leaves for implementation, after control.

* Necessity in the process of supervision by the Commissioner for the Civil Service Supervision, represents the establishment of uniform standards for all institutions involved in the civil service, which requires the inclusion in a special study of all institutions involved in the civil service, which should be carried out by the Department of Public Administration, as the institution charged by law to compile general policies in the field of civil service, as well as to administer the register of civil servants. This institution has the specialized capabilities and support with experts from the EU countries, to accomplish this task. In addition,, the Department of Public Administration, has all the possibilities, that based on this study, to propose to the Council of Ministers, the adoption of rules that are mandatory for all institutions involved in the civil service.

\section{References}

Baena, M. ((2005). Manual de Ciencia de la Administración. Síntesis, Madrid.

Bovaird, T. a. ( 2007 ). 'Civil service reform in the UK 1999-2005: revolutionary failure or evolutionary success. Public Administration, 85(2), 301-28.

Butcher, T. a. (2001). Modernising civil services. Public Policy and Administration, 16(3), 1-3.

Civil, K. i. (2013.). The annual report of the activity of the Civil Service Commission.

Denhardt, R. B. (2000). The new public service: serving rather than steering. Public Administration Review, 60(6) 549-59.

Garran, J. J. (2000). Handbook of State Government Administration. New York: Marcel Dekker.

Gary J., R. (2001). The situation of the civil service in Albania. Banka Botërore.

(2013). Law no.152 "On the Civil Servant".

(11.11.1999). Law No. 8549, "Civil Servant Status".

(07.07.2000). Instruction No. 2, "On the system of individual annual achievements of civil servants ". 
